\title{
OSTEOTOMY OF THE PROXIMAL END OF THE RADIUS FOR PARALYTIC SUPINATION DEFORMITY IN CHILDREN
}

\author{
A. L. Zaoussis, Athens, Greece \\ From the Rehabilitation Centre of the Hellenic Society for Crippled Children
}

Since Blount's (1940) paper on supination deformity of the forearm in children little has appeared in the literature about this condition.

Pronation is usually regarded as the most frequent and disabling deformity in the forearm and therefore has attracted more attention. Nevertheless a fixed supination deformity resulting from flaccid paralysis of the upper limb may impair the function of the limb at least as badly as a pronation deformity and the appearance of it is unsightly (Fig. 1). Furthermore, an otherwise good hand can be rendered useless if it hangs dorsiflexed, with the palm up.

A review of over 150 patients with early or residual obstetrical palsy at the Rehabilitation Centre of the Hellenic Society for Crippled Children in Athens revealed that approximately 14 per cent of patients had a fixed pronation of the forearm whereas 10 per cent had a fixed supination deformity. Six patients in the latter group were operated upon by the technique to be described.

The relatively high percentage of children with fixed supination was striking, but it was difficult to identify the causative factor. Since detailed muscle charts or a full previous history were not available in all the children one cannot determine whether supination was produced by pure muscle imbalance or by abuse of the classical "Statue of Liberty" splint which holds the arm in abduction and the forearm in supination. The latter seemed the more likely.

Supination deformity becomes fixed with alarming speed even when the "causative" splint is modified or discarded. Once established, this condition presents a problem even to the most skilled physiotherapist, and I do not know of any splint which, without being grotesque, will control a more or less fixed supination of the forearm.

Blount (1940) introduced closed osteoclasis of the middle third of both bones of the forearm for correction

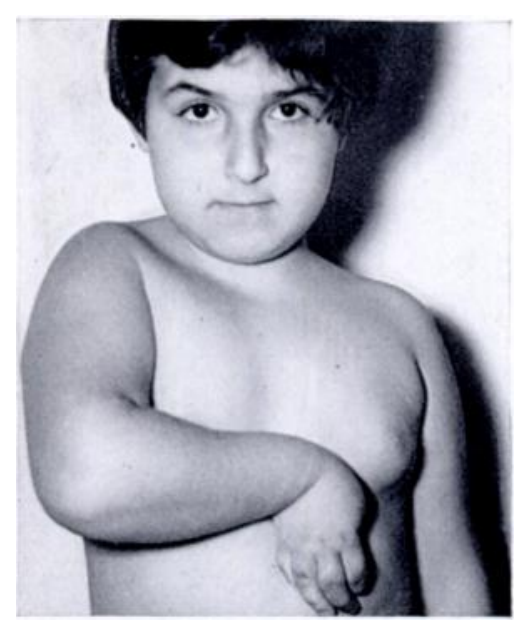

Fig. 1

Case 1-A girl of ten with fixed supination deformity of right forearm from obstetrical palsy.

of this deformity. In two out of his nine cases he had to repzat the osteoclasis later because of a recurrence of supination. According to Blount osteoclasis is easily performed because the bones are usually thin and porotic. However, he advised bending the bones "back and forth several times " and in one case he used a Thomas's wrench because the size of the bones made manual osteoclasis difficult.

Disliking closed osteoclasis, I decided to correct the deformity by open operation. Lange (1951) advocated osteotomy of the radial neck in cases of supination deformity resulting either from malunited forearm fractures or from poor positioning in ankylosis after pyogenic arthritis. I have employed his method in six cases with good results in all except one. Lange performed a transverse osteotomy two centimetres below the radial head. He then rotated the forearm into full pronation and let the osteotomy unite in this position. At first I followed his technique precisely and made an osteotomy as close to the radial head as possible. Later, particularly in younger children, the osteotomy was done farther down the bone for the fear of injuring the epiphysial plate. Nearly all the osteotomies were done either 
within the area of the radial tuberosity or below this point. Because of the supinator action of the biceps brachii only an osteotomy at or distal to its point of insertion should correct a supination deformity and prevent a recurrence. One should also remember that in radiographs of young children under five or six the ossific centre of the head has not yet appeared and miscalculations of the site of osteotomy are possible.

Lange warned against the illusion of creating free active rotation of the forearm through this operation and $I$ have also found it difficult to convince some parents that surgical intervention was aimed at restoring a better functional position, not to secure more movement in the forearm. After operation there was a very small range or no movement in all our cases. In this particular

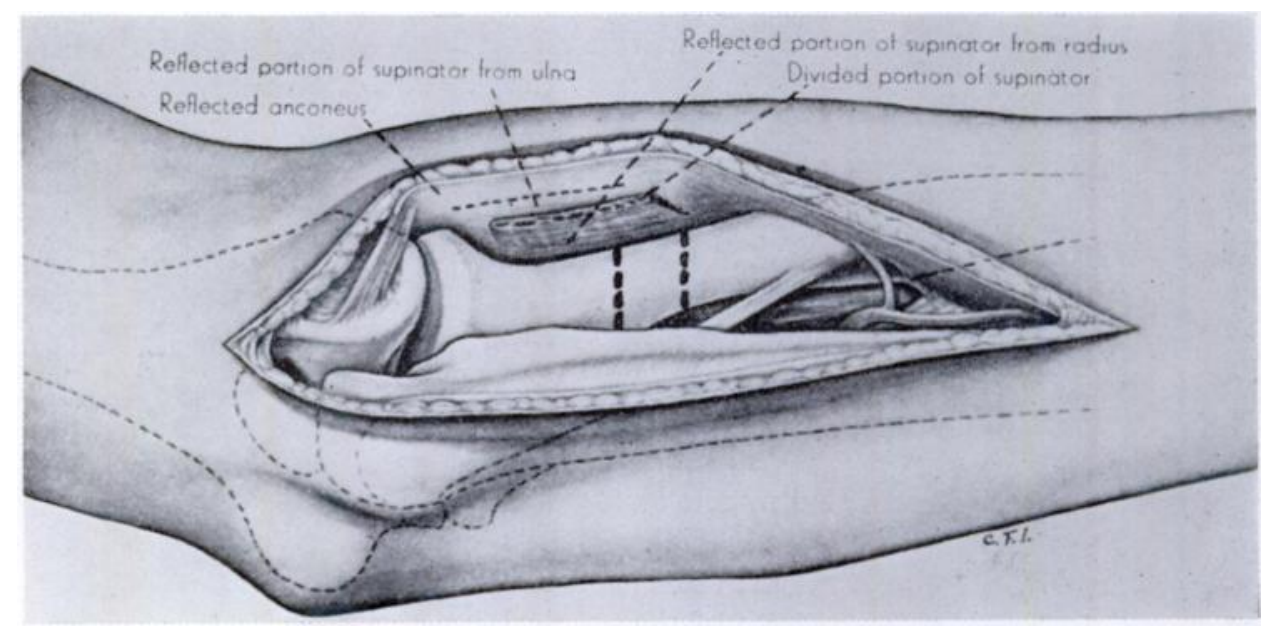

FIG. 2

Exposure of the proximal radius and interosseous membrane. The heavy interrupted lines indicate the choice of osteotomy sites. (After Boyd.)

respect Blount's osteoclasis appears a more pleasing method. He even observed an increase of the range of movement after osteoclasis technique. However, Blount stated: "It is evident that the best and most permanent results have been obtained in cases in which the chief desideratum is improvement of the cosmetic result." Obviously, in the difficult cases improvement of the position will only be obtained at the sacrifice of movement.

\section{TECHNIQUE OF OPERATION}

The proximal part of the radius is approached through the extensive exposure described by Boyd (1940) (Fig. 2). The proximal part of the incision does not have to be developed completely. Palpation of the radial head for orientation usually suffices.

This approach was selected for two reasons. Firstly because it automatically should release a contracture of the supinator muscle through partial division of its deep fibres; and secondly because it permits a good and safe exposure of the upper portion of the interosseous membrane which is occasionally contracted. Once the proximal radius is exposed subperiosteally a straightforward transverse osteotomy is carried out with an osteotome just distal to the radial tuberosity. The forearm is then brought into the position of greatest pronation by rotating the radius at the site of the osteotomy. If marked resistance to pronation is felt one may carefully proceed to divide the accessible part of the interosseous membrane. After closure of the wound a plaster is applied from the axilla to the metacarpo-phalangeal joints, with the elbow at a right angle and as much pronation of the forearm as possible. Pronation must be exaggerated in order to avoid recurrence of the deformity. A rapid loss of part of 
the correction obtained was noticed in almost all our cases shortly after operation. Blount had a similar experience. A period of four to six weeks' immobilisation is usually sufficient to ensure bony union of the osteotomy.

After removal of the plaster it would be prudent to provide the forearm with some type of protective splinting along with careful passive exercises. If reconstructive surgery is contemplated for paralysis in the hand it should be done after union of the osteotomy. Estimation of the hand's potentialities then will be easier and more accurate.

Illustrative cases are shown in Figures 3 to 7.

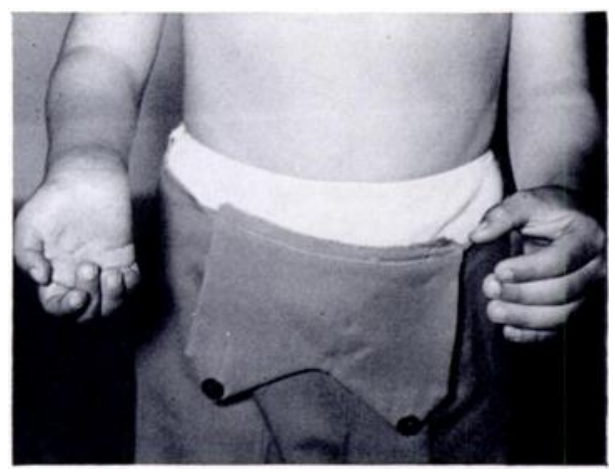

FIG. 3

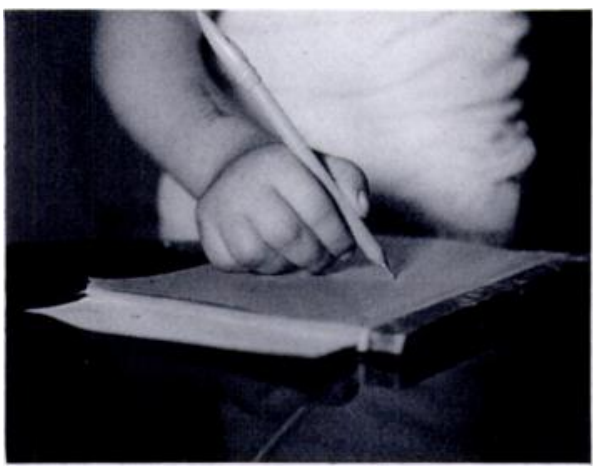

FIG. 4

Case 3-A boy of seven with residual obstetrical palsy. There is a severe supination deformity of right forearm and loss of opposition of the thumb. Figure 4-Osteotomy of the proximal radius brought the forearm into the neutral position. This was followed by surgical reconstruction of opposition (modified "opponodesis"). The function was greatly improved.

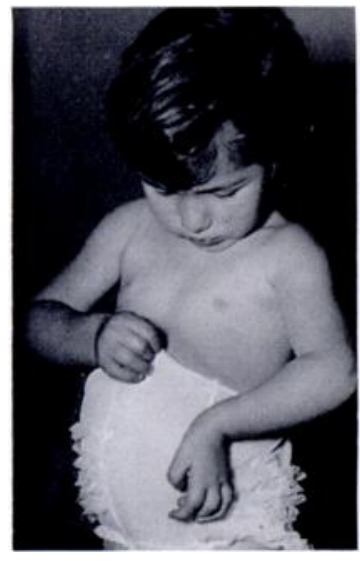

FIG. 5

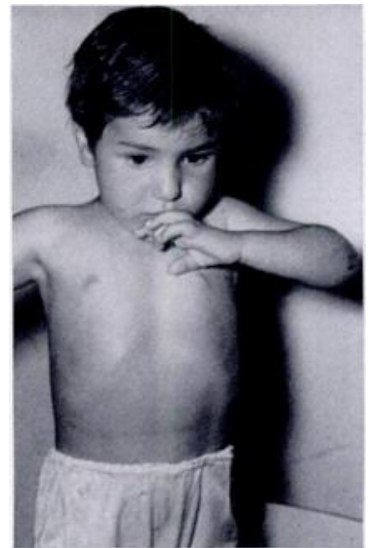

FIG. 6

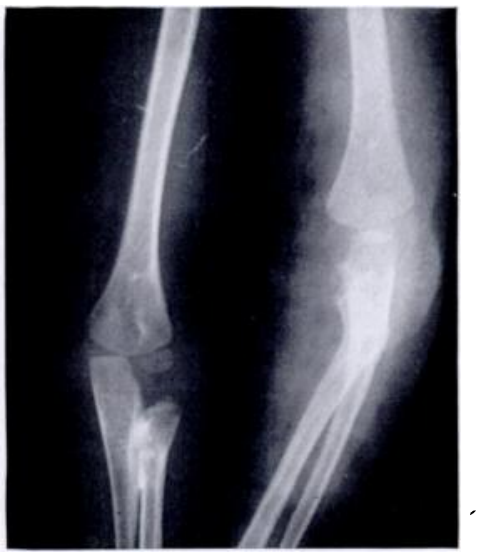

FIG. 7

Case 4-A girl of three with an ugly supination deformity of left forearm resulting from obstetrical palsy. The function was greatly impaired. Figure 6-After osteotomy. Cosmetically pleasing, and the function was substantially improved. Figure 7-Radiographs nine months after operation showing synostosis of the proximal radius and ulna. Moderate angulation persists.

\section{DISCUSSION}

With such a radical change in position of the forearm, from extreme supination into extreme pronation, some angulation or displacement of the bone ends at the osteotomy site is almost unavoidable. Nevertheless, the age of the children and the anatomy of this region would make the use of internal fixation rather hazardous. In all except one of our cases the osteotomy united within four or six weeks. In the one case in which delayed union led almost to a pseudarthrosis, 
TABLE I

Details of the Six Patients upon whom Operation was Performed

\begin{tabular}{|c|c|c|c|c|c|}
\hline $\begin{array}{c}\text { Case } \\
\text { number }\end{array}$ & Sex & $\underset{(\text { years })}{\text { Age }}$ & Diagnosis & Site of osteotomy & Other operations \\
\hline 1 & $\mathbf{F}$ & 10 & $\begin{array}{l}\text { Residual } \\
\text { obstetrical palsy }\end{array}$ & $\begin{array}{l}\text { Through } \\
\text { radial tuberosity } \\
\text { or just proximal to it }\end{array}$ & $\begin{array}{l}\text { Simultaneous tenodesis of flexor carpi } \\
\text { radialis and palmaris longus to control } \\
\text { drop of hand backward }\end{array}$ \\
\hline 2 & $\mathbf{M}$ & 3 & $\begin{array}{l}\text { Residual } \\
\text { obstetrical palsy }\end{array}$ & $\begin{array}{l}\text { Distal to } \\
\text { radial tuberosity }\end{array}$ & $\begin{array}{l}\text { Six months later release of medial } \\
\text { rotation contracture of same shoulder }\end{array}$ \\
\hline 3 & $\mathbf{M}$ & 7 & $\begin{array}{l}\text { Residual } \\
\text { obstetrical palsy }\end{array}$ & $\begin{array}{l}\text { Just distal to } \\
\text { radial tuberosity }\end{array}$ & $\begin{array}{l}\text { Three months later transference of } \\
\text { extensor pollicis brevis into extensor } \\
\text { carpi ulnaris with arthrodesis of } \\
\text { metacarpo-phalangeal joint of thumb } \\
\text { to restore active opposition }\end{array}$ \\
\hline 4 & $\mathrm{~F}$ & 3 & $\begin{array}{l}\text { Residual } \\
\text { obstetrical palsy }\end{array}$ & $\begin{array}{l}\text { Just distal to } \\
\text { radial tuberosity }\end{array}$ & - \\
\hline 5 & $\mathbf{M}$ & 9 & $\begin{array}{l}\text { Uncertain } \\
\text { (flaccid monoplegia) }\end{array}$ & $\begin{array}{l}\text { Proximal third } \\
\text { of radius }\end{array}$ & - \\
\hline 6 & $\mathbf{F}$ & 9 & $\begin{array}{l}\text { Residual } \\
\text { obstetrical palsy }\end{array}$ & $\begin{array}{l}\text { Proximal third } \\
\text { of radius }\end{array}$ & - \\
\hline
\end{tabular}

the clinical correction of the deformity was maintained throughout the period of non-union although immobilisation was discontinued in the seventh week. Six months after operation the bone ends are now spontaneously uniting. Clinically the osteotomy is solid and the cosmetic and functional results are satisfactory.

Even when angulation or displacement was not completely remodelled by growth, the clinical result remained unaffected. This also applies to two cases in which a synostosis of the proximal radius and ulna developed at a later stage (Fig. 7) and to the cases in which healing of the osteotomy produced permanent enlargement of the area of the radial tuberosity.

As noted earlier, cosmetic improvement and better functional position of the forearm, with this method, could be obtained only at the sacrifice of rotatory movement in the forearm. In fact, it seemed that the post-operative rigid resistance of the forearm to rotatory movement acted as a safeguard against recurrence of supination.

However paradoxical it may sound that loss of movement in the forearm can still be associated with good or even improved function, the fact remains that all except one of our patients showed good results both from a subjective and an objective assessment. Orthopaedic surgeons who have seen a great number of this type of deformity will appreciate the value of its correction. If the hand can be brought to the face or mouth in a proper line this alone is a gain. Rotatory movement is then not so important. The hand itself also benefits from this "derotation" of the forearm. Hidden potentialities are unveiled and delicate reconstructive procedures can be planned from a more favourable starting point (Figs. 3 and 4). Table I summarises the cases.

\section{SUMMARY}

1. Open osteotomy near the tuberosity of the radius to enable correction of fixed supination deformity of the forearm in children is an alternative to Blount's closed osteoclasis of both bones. 
TABLE I-continued

Detalls of the Six Patients upon whom Operation was Performed

\begin{tabular}{|c|c|c|c|}
\hline Follow-up & Objective assessment & Subjective assessment & Comments \\
\hline 3 years & $\begin{array}{l}80 \text { per cent recurrence of } \\
\text { deformity 6-8 weeks after } \\
\text { operation }\end{array}$ & - & $\begin{array}{l}\text { Possible causes of failure: osteotomy } \\
\text { too proximal and tenodesis failed. } \\
\text { Probably hyperextended wrist } \\
\text { dragged forearm back into supina- } \\
\text { tion. Propose to arthrodese wrist } \\
\text { and repeat osteotomy }\end{array}$ \\
\hline $\begin{array}{l}2 \text { years } \\
2 \text { months }\end{array}$ & $\begin{array}{l}\text { Forearm in neutral position. } \\
\text { No rotation. Synostosis of } \\
\text { proximal radius and ulna }\end{array}$ & $\begin{array}{l}\text { Appearance improved. } \\
\text { Function improved }\end{array}$ & - \\
\hline 13 months & $\begin{array}{l}\text { Forearm in neutral position. } \\
\text { Minimal rotation }\end{array}$ & $\begin{array}{l}\text { Appearance improved. } \\
\text { Function greatly } \\
\text { improved }\end{array}$ & - \\
\hline 9 months & $\begin{array}{l}\text { Forearm in neutral position. } \\
\text { No rotat ory movements. } \\
\text { Synostosis of proximal radius } \\
\text { and ulna }\end{array}$ & $\begin{array}{c}\text { Appearance } \\
\text { greatly improved. } \\
\text { Function } \\
\text { substantially improved }\end{array}$ & - \\
\hline 9 months & $\begin{array}{l}\text { Forearm in } 30 \text { degrees of pro- } \\
\text { nation. } 15 \text { degrees of active } \\
\text { rotatory movement both ways }\end{array}$ & $\begin{array}{l}\text { Appearance improved. } \\
\text { Grasps better. Can } \\
\text { place hand in pocket }\end{array}$ & $\begin{array}{l}\text { Transient paresis of dorsal inter- } \\
\text { osseous nerve which recovered }\end{array}$ \\
\hline 6 months & $\begin{array}{l}\text { Forearm in neutral position. } \\
15 \text { degrees of passive rotation } \\
\text { of forearm }\end{array}$ & $\begin{array}{l}\text { Parents pleased with } \\
\text { appearance. Uses hand } \\
\text { more in eating and grasping }\end{array}$ & $\begin{array}{l}\text { Delayed union of osteotomy which } \\
\text { took six months to heal }\end{array}$ \\
\hline
\end{tabular}

2. In five out of six cases with residual obstetrical palsy substantial correction of the deformity was maintained.

3. The cosmetic result was impressive, especially in girls, but an improved function was also observed. If the hand is paralysed, correction of supination facilitates reconstruction.

4. Complications such as angulation, displacement, delayed union and synostosis of the proximal radius and ulna did not affect the final results.

5. With the method described a more or less permanent "blocking" of rotatory movement in the forearm was observed but this did not seem to impair the functional result.

The author wishes to express his gratitude to Mr M. Dimitsas, Orthopaedic Consultant at the Asklepiion Voula Hospital, for allowing him to operate and follow up the patients at his department.

\section{REFERENCES}

Blount, W. P. (1940): Osteoclasis for Supination Deformities in Children. Journal of Bone and Joint Surgery, 22, 300 .

BoyD, H. B. (1940): Surgical Exposure of the Ulna and Proximal Third of the Radius through one Incision. Surgery, Gynecology and Obstetrics, 71, 86.

Campbell’s Operative Orthopaedics (1956): Third edition, Volume 2, pp. 1,347 and 1,814. London: Henry Kimpton.

Köhler, A., and Zimmer, E. A. (1956): Grenzen des Normalen und Anfänge des Pathologischen im Röntgenbilde des Skelettes. Tenth edition (by E. A. Zimmer), p. 120. Stuttgart: Georg Thieme Verlag.

LANGE, M. (1951): Orthopädisch-Chirurgische Operationslehre, p. 344. München: Verlag von J. F. Bergmann. 